Article

\title{
Investigating the Impact of Particle Size on the Performance and Internal Resistance of Aqueous Zinc Ion Batteries with a Manganese Sesquioxide Cathode
}

\author{
Christian Bischoff ${ }^{1, *}$, Oliver Fitz ${ }^{1}$, Christian Schiller ${ }^{1}$, Harald Gentischer ${ }^{1}$, Daniel Biro ${ }^{1}$ and \\ Hans-Martin Henning ${ }^{2}$ \\ 1 Battery Cell Technology, Department of Electrical Energy Storage, Fraunhofer Institute for Solar Energy \\ Systems ISE, Heidenhofstraße 2, 79110 Freiburg im Breisgau, Germany; Oliver.Fitz@ise.fraunhofer.de (O.F.); \\ Christian.Schiller@ise.fraunhofer.de (C.S.); Harald.Gentischer@ise.fraunhofer.de (H.G.); \\ Daniel.Biro@ise.fraunhofer.de (D.B.) \\ 2 Chair of Solar Energy Systems, Institute for Sustainable Technical Systems (INATECH), University of \\ Freiburg, Emmy-Noether-Straße 2, 79110 Freiburg im Breisgau, Germany; \\ Hans-Martin.Henning@ise.fraunhofer.de \\ * Correspondence: Christian.Bischoff@ise.fraunhofer.de; Tel.: +49-761-4588-5046
}

Received: 1 August 2018; Accepted: 28 August 2018; Published: 11 September 2018

\begin{abstract}
Aqueous zinc ion batteries are considered to be one of the most promising battery types for stationary energy storage applications. Due to their aqueous electrolyte, they are inherently safe concerning flammability and environmentally friendly. In this work, the strong influence of the particle size of manganese sesquioxide on the performance of the battery is investigated. Ball milling was used to decrease the particle diameter. The resulting powders were used as active material for the cathodes, which were assembled in coin cells as full cells together with zinc foil anodes and aqueous electrolyte. It was shown that about one third of the original particle size can nearly triple the initial capacity when charged with constant current and constant end-of-charge voltage. Additionally, smaller particles were found to be responsible for the collapse of capacity at high current densities. By means of electrochemical impedance spectroscopy, it was shown that particle size also has a large impact on the internal resistance. Initially, the internal resistance of the cells with small particles was about half that of those with big particles, but became larger during cycling. This reveals accelerated aging processes when the reactive surface of the active material is increased by smaller particles.
\end{abstract}

Keywords: rechargeable aqueous zinc-ion battery; aqueous electrolyte; stationary energy storage; manganese sesquioxide; particle size; internal resistance

\section{Introduction}

Rechargeable batteries with aqueous electrolytes have recently received much attention because of their inherent safety, fast ion kinetics, low cost materials and environmental friendliness [1-3]. With these qualities, they are well suited for large-scale energy storage applications, where gravimetric and volumetric parameters of the battery are playing a minor role compared to mobile and automotive applications. Recently, many different aqueous cell chemistries have been investigated [4]. Aqueous lithium [5,6], sodium [7-9], zinc/sodium hybrid batteries [10-14] and multivalent ion batteries [15,16] have been discovered. Together with magnesium, calcium and aluminum, zinc ion batteries belong to the class of metallic multivalent ion batteries. Metallic multivalent ion batteries are among the most promising rechargeable aqueous batteries due to their high energy density, which can be two to three times higher than that of monovalent aqueous batteries like lithium and sodium aqueous batteries [4,17]. In aqueous zinc ion batteries, the use of a metallic zinc anode is possible. This is a 
great advantage compared to aqueous lithium and sodium batteries because of the relatively high theoretical specific capacity of about $820 \mathrm{mAh} / \mathrm{g}[18,19]$, the resource abundance and the safety of zinc (unlike magnesium or lithium, there is no rapid oxidation of zinc when exposed to ambient air). On the other hand, zinc tends to build up dendrites and may be passivated by the precipitation of zinc oxide [20]. The risk of dendrite growth may be reduced by using zinc foams as anodes [21-23]. The precipitation of zinc oxide may be handled by adjusting an acidic $\mathrm{pH}$ value [24]. The exact $\mathrm{pH}$ value avoiding zinc oxide or zinc hydroxide precipitation can be determined using potential-pH diagrams [25,26].Manganese oxide, in general, is seen as a promising host material to insert these multivalent ions into because of its high capacity and energy density [4]. Recently, the investigation of new materials has attracted much attention in this field of research. In order to find high capacity cathode materials, manganese oxides like $\alpha-\mathrm{MnO}_{2}$ [27], $\delta-\mathrm{MnO}_{2}$ [28], $\mathrm{Mn}_{3} \mathrm{O}_{4}$ [29], $\alpha-\mathrm{MnO}_{2}$ nano rods [30-32], $\beta-\mathrm{MnO}_{2}$ nano rods [33] and electrodeposited $\mathrm{MnO}_{2}$ [34] have been investigated. In this work, we would like to take an initial step that focuses on the production parameters for such large-scale energy storage battery cells. It is well known that battery production parameters like the water content of the electrode slurry, the electrode coating thickness and the particle size of the active material affects the electrode morphology and therefore the overall battery performance. In particular, the particle size influences capacity, coulomb efficiency as well as ion-diffusion and electron transport [35-38]. Comparable studies show that smaller manganese dioxide particles may have an even higher open circuit voltage but a strongly accelerated capacity drop [39]. Moreover, the mean particle size of manganese dioxide can change during cycling, depending on the reduction or oxidation state of the cathode [40]. In this study, we investigate the impact of particle size of the active material in the cathode on the performance and internal resistance of aqueous zinc ion batteries with a metallic zinc anode and a manganese sesquioxide cathode. Manganese sesquioxide was chosen because of its promising characteristics and high specific capacity of $150 \mathrm{mAh} \mathrm{g}^{-1}$ [41]. In the work by Jiang et al. (2017) [41] the zinc ion storage mechanism was revealed. Manganese sesquioxide faces a phase transition from bixbyite structure to layered birnessite. Zinc ions are inserted between those layers. In the work by Jiang et al. (2017) [41] the chemical reaction is described as follows:

- Cathodic reaction: $x \mathrm{Zn}^{2+}+2 \mathrm{xe}^{-}+\mathrm{Mn}_{2} \mathrm{O}_{3} \rightleftharpoons \mathrm{Zn}_{\mathrm{x}} \mathrm{Mn}_{2} \mathrm{O}_{3}$

- Anodic reaction: $x Z n \rightleftharpoons x Z n^{2+}+2 x e^{-}$

- Overall reaction $\mathrm{Mn}_{2} \mathrm{O}_{3}+x \mathrm{Zn} \rightleftharpoons \mathrm{Zn}_{x} \mathrm{Mn}_{2} \mathrm{O}_{3}$

According to Faraday's law, the theoretical capacity of manganese sesquioxide is $340 \mathrm{mAh} \mathrm{g}^{-1}$ if two electrons are exchanged per structural unit (reduction of $\mathrm{Mn}$ (III) to $\mathrm{Mn}(\mathrm{II})$ ), whereas manganese dioxide is theoretically limited to $308 \mathrm{mAh} \mathrm{g}^{-1}$. This shows that the theoretical capacity of manganese sesquioxide has clearly not yet been exploited, so further investigations are important.

\section{Experimental Setup}

The manganese sesquioxide material was purchased from Alfa Aesar (Ward Hill, MA, USA). The particles were downsized by ball milling using zirconium oxide balls with a diameter of $2 \mathrm{~mm}$. A $250 \mathrm{~mL}$ grinding beaker was filled with water, manganese sesquioxide and zirconium balls with a mass ratio of 4:1:10. The circumferential speed was fixed at 500 rounds per minute. The total grinding time was subdivided into one-minute intervals, with a pause of $30 \mathrm{~s}$ to avoid any undesirable heating. The net grinding time was $15 \mathrm{~min}$. The particle size was analyzed using the laser diffraction analyzer LS 13320 by Beckman Coulter, with a $5 \mathrm{~mW}$ laser diode of $750 \mathrm{~nm}$ wavelength. The Fraunhofer optical model (forma factor 1 ) was used. The sample powders were mixed in water (refractive index 1.332). Afterwards, the manganese sesquioxide was mixed with binder (LA133) and carbon black with a mass ratio of the solid components of 7:1:2 and water ( $350 \mathrm{wt} \%$ based on the mass of the solid components) to get a slurry. The cathode slurry was coated on a stainless-steel foil. The wet coating thickness of about $200 \mu \mathrm{m}$ was controlled by the coating mask: the coating knife was installed in a height of $200 \mu \mathrm{m}$. Subsequently, the coating was dried in an oven at $80^{\circ} \mathrm{C}$ overnight under ambient conditions. 
The dried cathodes had a thickness of $\sim 60 \mu \mathrm{m}$ and a mass load of $\sim 4.25 \mathrm{mg} \mathrm{cm}^{-2}$. The cathodes were put into CR2025 coin cell cases with a glass fiber separator and metallic zinc foil as the anode. The zinc foil was cleaned, in advance, with diluted salt acid. The electrolyte consisted of an aqueous solution of $2 \mathrm{M}$ zinc sulfate and $0.1 \mathrm{M}$ manganese sulfate as an additive. Subsequently, the battery cells were cycled with different current densities in a BioLogic Science Instruments BCS battery tester. The electrochemical impedance spectroscopy (EIS) was performed on the same potentiostat with an amplitude of $10 \mathrm{mV}$ in the frequency range from $10 \mathrm{kHz}$ down to $50 \mathrm{mHz}$. The cells were examined in charged state and rested for $5 \mathrm{~min}$ after charging. The EDX measurements were conducted using a Bruker Nano GmbH-Quantax EDX with an acceleration voltage of $5 \mathrm{kV}$. On the same device, the SEM pictures were recorded in 2000-fold magnification.

\section{Results and Discussion}

The particle size distribution was analyzed by laser diffraction analysis. In Figure 1, the results of the two samples are shown. The ball milling time of $15 \mathrm{~min}$ net, led to an average particle size of about one third compared to the original size. For further information of the mean particle size values see the Supplementary Information (Table S1).

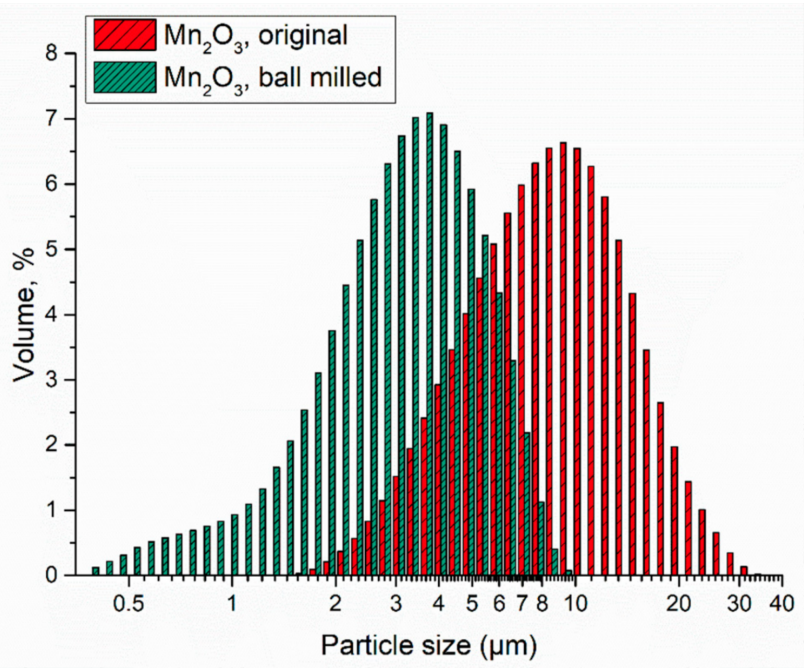

Figure 1. Particle size distribution of the $\mathrm{Mn}_{2} \mathrm{O}_{3}$ in original state as purchased (original) and after the ball milling process (ball milled).

In order to test the quality of the coated electrodes, scanning electron microscope (SEM) images were taken of both electrodes. Figure 2a shows the electrode with the original particle size. Energy-dispersive X-ray spectroscopy (EDX) revealed that the larger particles are made of manganese sesquioxide (Supplementary Information Figures S1 and S2).

Figure $2 \mathrm{~b}$ displays the structure of the unmilled manganese sesquioxide, before cycling, in a close-up view. In Figure 2c, the image of the coated electrode with small particles is shown. Both electrodes (Figure 2a,c) show a homogenous particle distribution and no major cracks. Some particle samples were sized optically to verify the laser diffraction analysis measurements. In Figure $2 \mathrm{~d}$, a close-up view of the ball milled manganese sesquioxide particles is revealed. This structure is comparable to the unmilled one in Figure $2 \mathrm{~b}$, so the ball milling process did not significantly change the surface structure of the particles. 


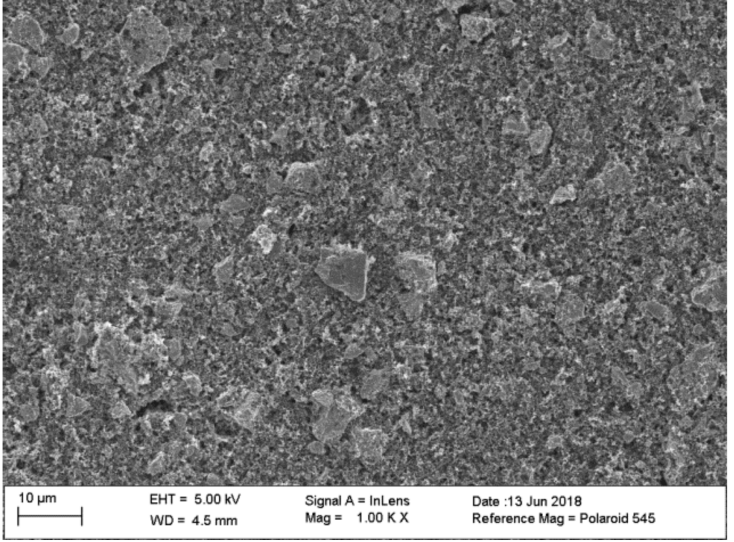

(a)

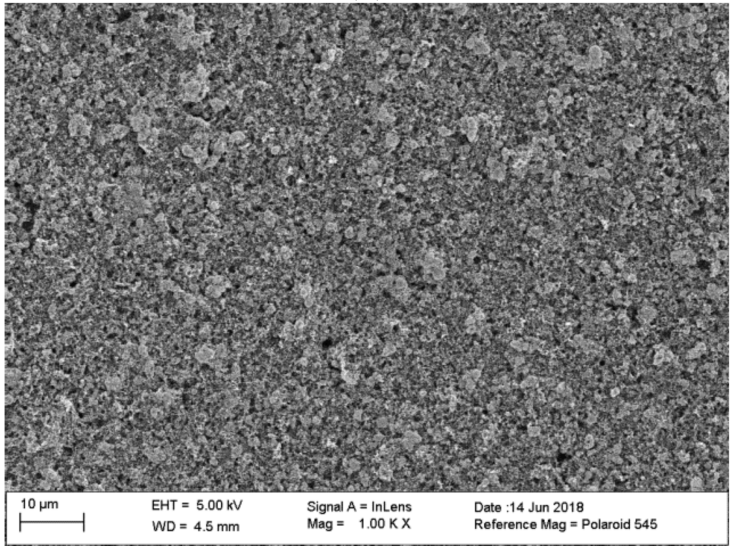

(c)

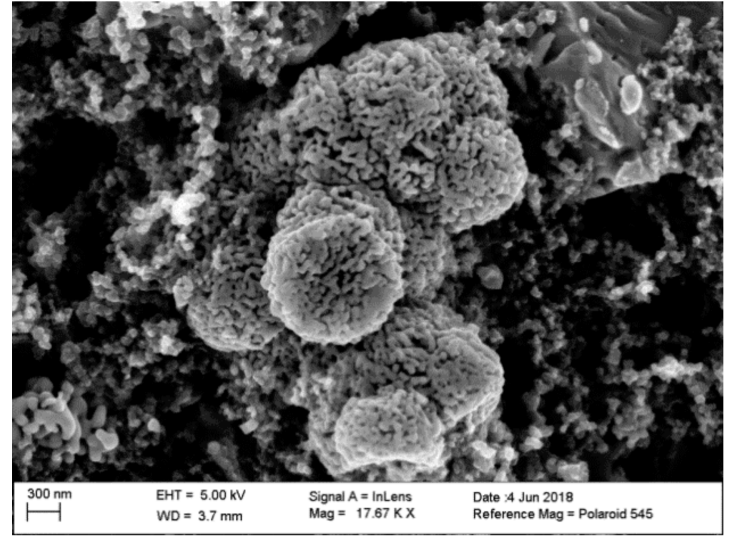

(b)

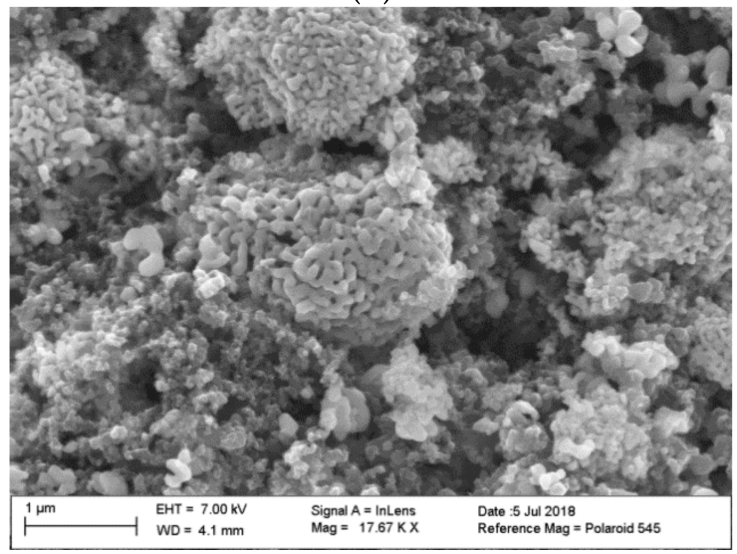

(d)

Figure 2. (a) Electrode surface with manganese sesquioxide particles in the original state, before cycling; (b) close-up view of manganese sesquioxide particle, unmilled/orignal state, before cycling; (c) electrode surface with mangenese sesquioxide particles after ball milling for 15 min net time, before cycling; (d) close-up view of manganese sesquioxide particle after ball milling for 15 min net time, before cycling.

The results of the rate capability tests are shown in Figure 3. Different current densities were applied to the coin cells. The current densities were calculated according to the mass of the active material in the electrode. Figure 3a shows the voltage curves of the batteries. An initial discharge/charge step with an applied current density of $50 \mathrm{~mA} \mathrm{~g}^{-1}$ was performed. The initial discharge step includes the typical formation process. In the following, charge and discharge capacities were recorded at current densities of 100, 200, 300, 500, 1000, 2000 and again at $100 \mathrm{~mA} \mathrm{~g}^{-1}$. Regarding the capacity curves of the rate capability test in Figure $3 b$, the initial capacity of the battery cell with the smaller particles was nearly tripled in comparison to the one with the original particle size. During the first 30 cycles, a significant capacity loss occurred for the ball milled particles. Only $65 \%$ of the initial capacity remained, whereas the electrode with particles of the original, larger size kept its capacity and even increased. During the cycles with higher current densities, the specific capacity of the electrode with small particles broke down at $10 \mathrm{mAh} \mathrm{g}^{-1}$ at $500 \mathrm{~mA} \mathrm{~g}^{-1}$. At $1000 \mathrm{~mA} \mathrm{~g}^{-1}$ it was not possible to save any charge in the battery because the end-of-charge voltage was reached immediately. 


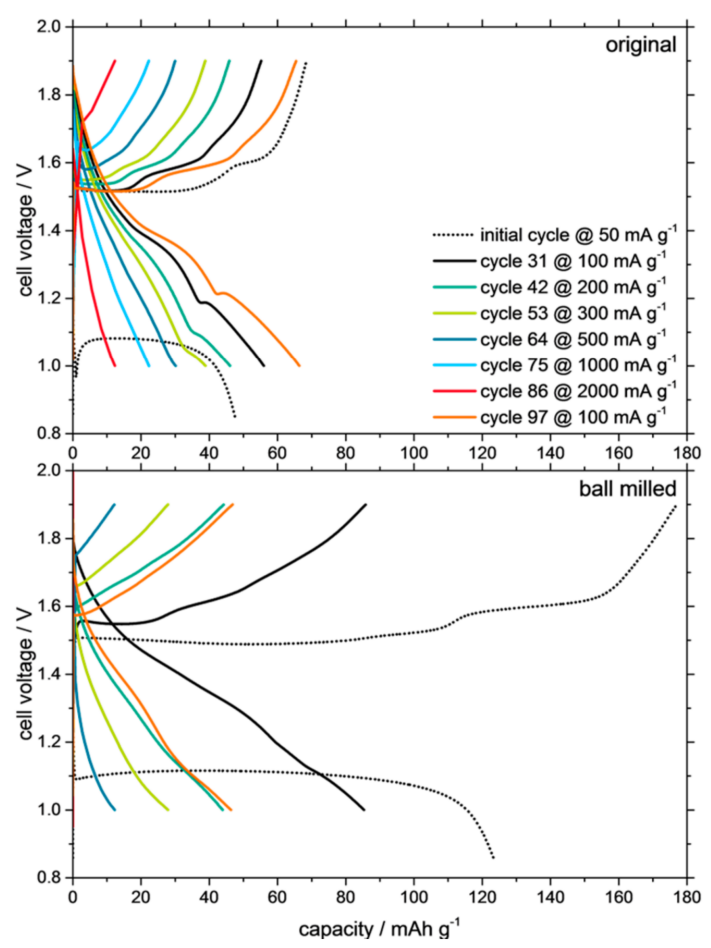

(a)

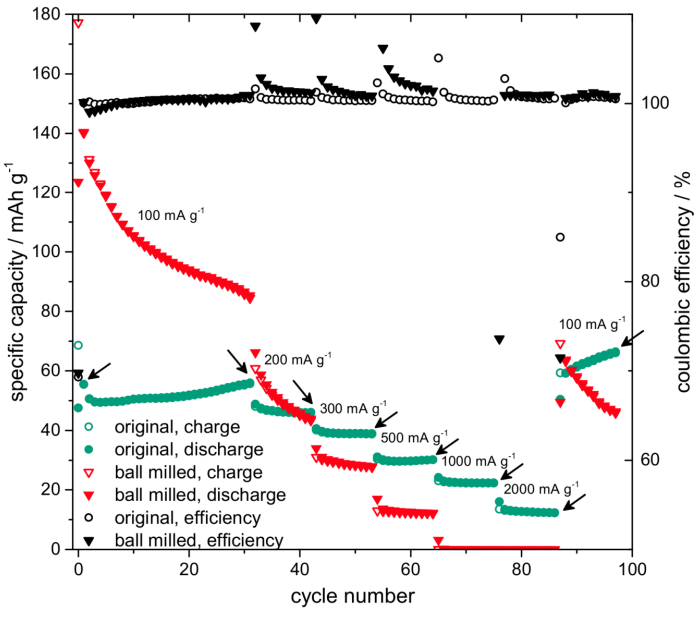

(b)

Figure 3. Cell voltage curves of the rate capability test for the batteries with original and ball milled active material (a) are compared. Changes in specific capacity (b) are shown. The arrows mark the cycles when the potential curves (a) were registered.

In contrast, the battery cell with larger particles remained stable during the cycles with high current densities; at least $10 \mathrm{mAh} \mathrm{g}^{-1}$ remained at $2000 \mathrm{~mA} \mathrm{~g}^{-1}$. After the cycles with high current densities, the low current density of $100 \mathrm{~mA} \mathrm{~g}^{-1}$ was applied again, for ten cycles, to test the state of health of the battery cells. It was revealed that the battery with smaller particles was still working but suffering strong capacity losses, whereas the battery cell with the larger particles had an increasing specific capacity and showed no signs of aging but on a lower level of capacity. The generally lower capacity of the larger active material particles can be ascribed to longer diffusion paths within the particles, causing longer processing time. Due to the fixed voltage limits, less capacity can be transferred into the active material during the provided processing time.

During the last cycles, the specific capacity of the battery cell with the larger particles was approximately $10 \%$ higher than that of the smaller particles.

Coulombic efficiencies above $100 \%$ can be observed right after switching the current density to a higher level (Figure 3b). This means that the discharge capacity exceeds the charge capacity during these first cycles of the higher current density phase. During the low current densities, the specific capacity of the active material is significantly higher than that at high current densities (cf. e.g., $100 \mathrm{~mA} / \mathrm{g}$ to $200 \mathrm{~mA} / \mathrm{g}$ ). The next current density phase (with a higher current density) starts with a discharge phase (this is because the first formation step of this battery chemistry is always a discharge step). At this moment, the battery has a relatively higher charge, and the discharge capacity is higher than the following charge capacity by which the discharge capacity is compared in the coulombic efficiency equation. This surplus charge from the previous lower current density phase fades during the following, higher current density phase.

In order to analyze the reason for these strong capacity losses of smaller particles, and the capacity growth of larger particles, the internal resistance of the battery cells was measured with electrochemical impedance spectroscopy (EIS). EIS measurements were applied after the 1st (current density $\left.50 \mathrm{~mA} \mathrm{~g}^{-1}\right)$, 31st $\left(100 \mathrm{~mA} \mathrm{~g}^{-1}\right)$, and 97 th $\left(100 \mathrm{~mA} \mathrm{~g}^{-1}\right)$ cycle to note any changes 
during cycling. The first EIS measurement at a low current density of $50 \mathrm{~mA} \mathrm{~g}^{-1}$ should show the initial state of the battery without any aging and cycling effects. The results of the measurements are plotted as Nyquist-Diagrams in Figure 4.

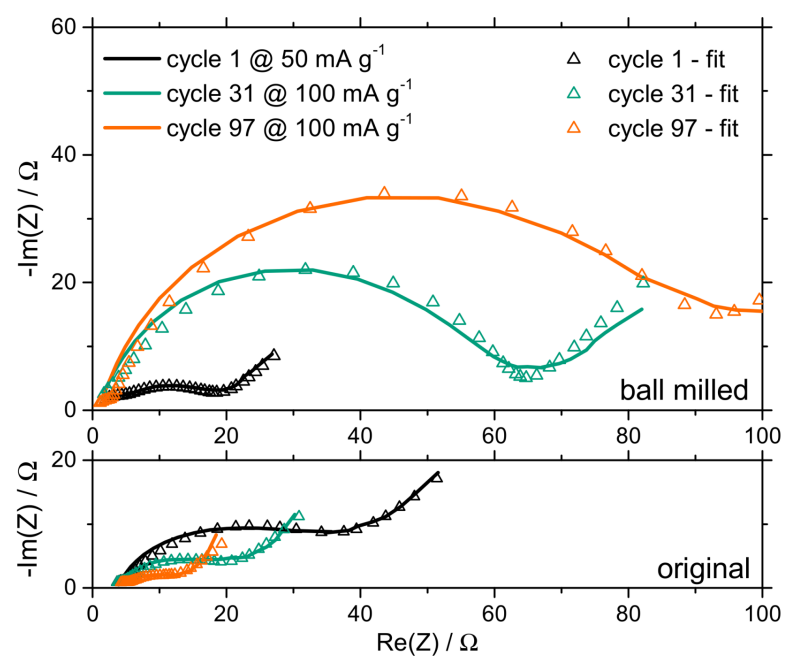

Figure 4. Nyquist diagrams of the electrochemical impedance spectroscopy (EIS) measurements during cycling of the two battery cell samples. In the upper diagram, the results of the cell with the ball milled active material can be seen. In the lower part, the results of the cell with the unmilled particles are shown.

These experimental results were fitted by an equivalent circuit model to obtain a better understanding of the changes in the internal resistance during cycling. The equivalent circuit model can be seen in Figure 5. The values of every element are shown in the Supplementary Information (Table S2). $R_{\mathrm{ct} 1}$ describes the charge transfer resistance of the zinc anode and was kept constant after the first fit. This is due to the assumption that the aging process is mainly visible at the cathode, which is described by the $R_{\mathrm{ct} 2}$.

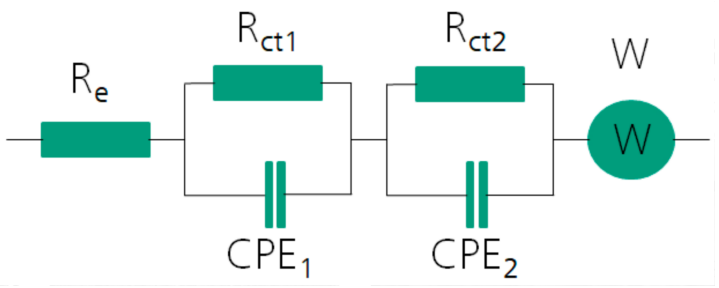

Figure 5. Equivalent circuit model that was used for fitting the data of the electrochemical impedance spectroscopy. $R_{e}$ is dedicated to the electrolyte resistance, $R_{c t}$ and CPE (Constant Phase Element) show charge transfer reactions of the solid/solution interfaces and W (Warburg element) describes diffusion-controlled processes like the ionic diffusion in the porous cathode structure.

Figure 4 demonstrates that the resistive component of the impedance $\left(R_{e}\right.$, where the left side of the semi circles intercept the x-axis) in the battery cell with the small particles is slightly smaller than the one with larger particles. This can be explained by the higher electrical conductivity of the electrode with small manganese sesquioxide particles. The better distribution of these low conductive active materials in the bulk electrode shortens the electronic paths of the carbon black by lowering their tortuosity. This ohmic part stays constant during cycling, which means that the structure of the electrode is not destroyed or damaged during cycling. Regarding the entire resistive component of the battery cell, $\left(R_{e}+R_{c t 1}+R_{c t 2}\right.$, $x$-axis intercept with the semicircles, Table 1$)$ the initial internal 
resistance of the battery with the ball milled particles is about $50 \%$ smaller than that of the battery with the original particle size. The main reason can be seen in the changed charge transfer resistance. The higher exchange surface in the electrode with the small particles decreases the charge transfer resistance during the first cycle.

Table 1. Sum of resistive components $\left(R_{c t 1}+R_{c t 2}\right)$ of the impedance of the two battery cells at different cycle numbers.

\begin{tabular}{ccc}
\hline Cycle Number & $\begin{array}{c}\text { Big Particles } \\
(\boldsymbol{\Omega})\end{array}$ & $\begin{array}{c}\text { Small Particles } \\
(\boldsymbol{\Omega})\end{array}$ \\
\hline 1 & 33.20 & 18.48 \\
31 & 17.47 & 61.87 \\
97 & 9.58 & 85.46 \\
\hline
\end{tabular}

The charge transfer resistance increased significantly after the 31st cycle in the battery cell with the ball milled particles (about 300\%), whereas the battery cell with the bigger particles showed a decreasing charge transfer resistance. In the unmilled sample, the charge transfer resistance was halved by the 31st cycle. This tendency can also be observed at the last cycle ( $97 \mathrm{th})$. This decrease in the battery with unmilled particles can be interpreted as the phase transformation of manganese sesquioxide, which was thoroughly explained by Jiang et al. (2017) [41]. The slowly changing manganese sesquioxide phase lowers the charge transfer resistance, whereas in the smaller particles this process must be finished during the first cycles and cannot be seen in further cycles. Clearly, the small particles start to age earlier. A possible explanation for the strong capacity losses of the smaller particles could be that the increasing internal charge transfer resistance is a reason for overpotentials. Charging/discharging with constant current up/down to fixed voltages limits the available time for the charge transfer. Consequently, an increasing charge transfer resistance leads to a decreasing cell capacity because the voltage limits are reached earlier.

After cycling, the coin cells were opened to examine the cathodes more closely. The cathodes were thoroughly washed with distilled water. Figure 6a,c shows no major cracks or damage of the electrode coating, which was already indicated by the constant $R_{e}$ resistance. The filaments on the SEM images are separator fibers. In Figure 6b, a close-up view shows that the unmilled particles formed a clear flake structure as described in Jiang et al.'s work (2017) [41]. In Figure 6d, the ball milled particles do not show a formation of such a flake structure which might explain the largely increasing charge transfer resistance. This indicates that the aging process of the material was heavily accelerated by ball milling the particles.

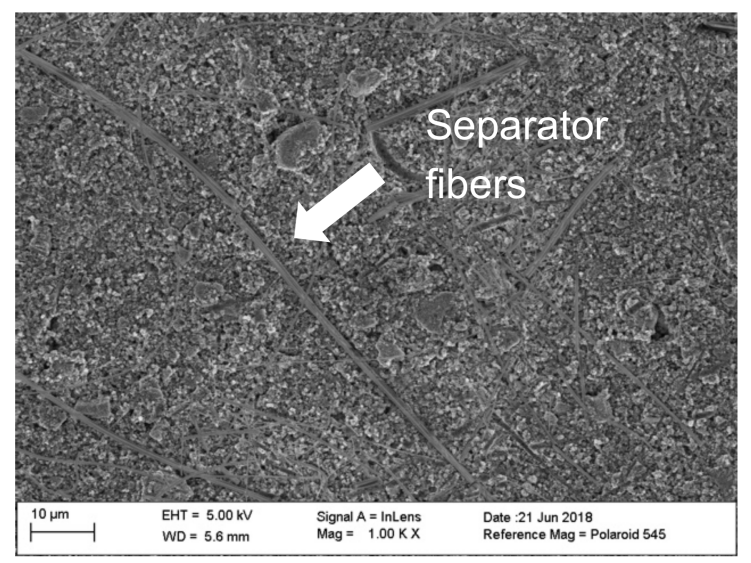

(a)

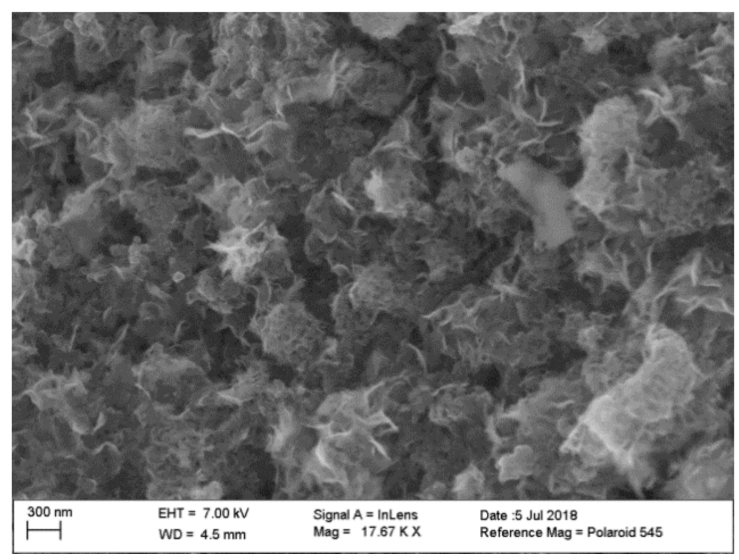

(b)

Figure 6. Cont. 


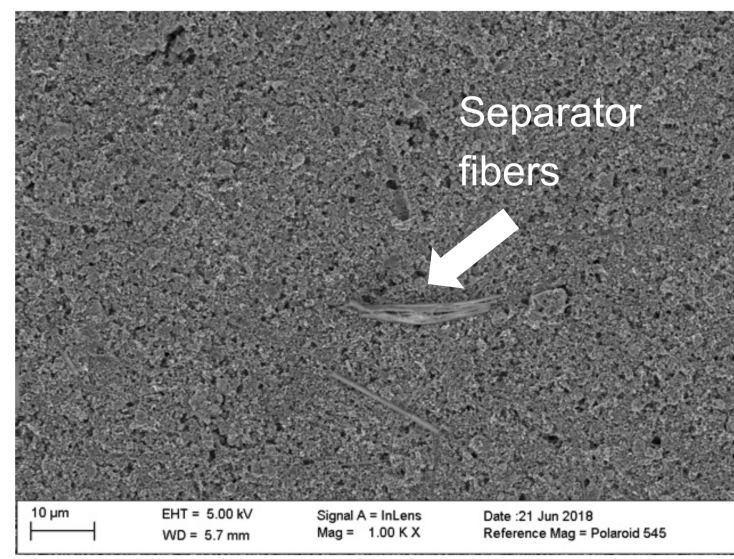

(c)

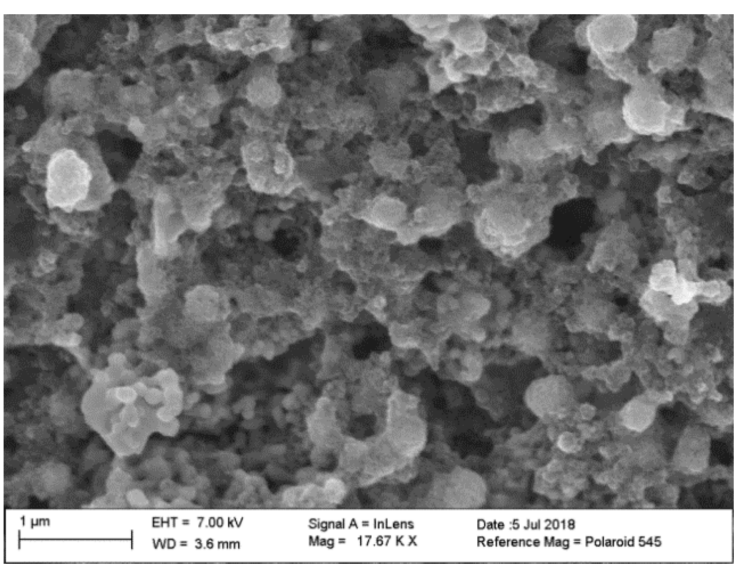

(d)

Figure 6. (a) Electrode surface with manganese sesquioxide particles in the original state, after cycling; (b) close-up view of manganese sesquioxide particles, unmilled, after cycling; (c) electrode surface with mangenese sesquioxide particles after ball milling for 15 min net time, after cycling; (d) close-up view of manganese sesquioxide particle, ball milled, after cycling.

\section{Conclusions}

This work shows that ball milling, i.e., decreasing the particle size of manganese sesquioxide, has a large impact on the initial capacity of aqueous zinc ion batteries. The specific capacity can be nearly tripled (from $50 \mathrm{mAh} \mathrm{g}^{-1}$ to $140 \mathrm{mAh} \mathrm{g}^{-1}$ ) by ball milling the manganese sesquioxide particles down to about one third of the original size. Small particles show a greater reactive, or rather catalytic, surface leading to kinetically accelerated aging processes and an increasing charge transfer resistance. Consequently, the cell capacity decreases by reaching the voltage limits earlier. In contrast, bigger particles show a lower, but more stable, capacity development and even a decreasing internal charge transfer resistance. The formation of an already known flake structure on the particles might explain this decrease.

Supplementary Materials: The following are available online at http:/ / www.mdpi.com/2313-0105/4/3/44/s1, Figure S1: EDX SEM image, Figure S2: EDX diagram, Table S1: particle size distribution, Table S2: equivalent circuit modelling.

Author Contributions: Conceptualization, C.B. and O.F.; Data curation, O.F.; Formal analysis, C.S.; Funding acquisition, H.G., D.B. and H.-M.H.; Investigation, C.B.; Methodology, C.B., O.F.; and C.S.; Project administration, D.B.; Resources, H.G.; Software, O.F. and C.S.; Supervision, H.-M.H.; Validation, C.B., O.F. and C.S.; Visualization, O.F.; Writing—original draft, C.B.; Writing—review \& editing, H.G., D.B. and H.-M.H.

Funding: Part of this work was supported by the Wirtschaftsministerium Baden-Württemberg in the research project NAWIN.

Acknowledgments: Christian Bischoff acknowledges the Heinrich Böll Stiftung for the support.

Conflicts of Interest: The authors declare no conflict of interest.

\section{References}

1. Trócoli, R.; La Mantia, F. An aqueous zinc-ion battery based on copper hexacyanoferrate. ChemSusChem 2015, 8, 481-485. [CrossRef] [PubMed]

2. Zhu, C.; Fang, G.; Zhou, J.; Guo, J.; Wang, Z.; Wang, C.; Li, J.; Tang, Y.; Liang, S. Binder-free stainless steel@ $\mathrm{Mn}_{3} \mathrm{O}_{4}$ nanoflower composite: A high-activity aqueous zinc-ion battery cathode with high-capacity and long-cycle-life. J. Mater. Chem. A 2018, 6, 9677-9683. [CrossRef]

3. Liu, C.; Wang, X.; Deng, W.; Li, C.; Chen, J.; Xue, M.; Li, R.; Pan, F. Engineering Fast Ion Conduction and Selective Cation Channels for a High-Rate and High-Voltage Hybrid Aqueous Battery. Angew. Chem. Int. Ed. 2018, 57, 7046-7050. [CrossRef] [PubMed] 
4. Liu, J.; Xu, C.; Chen, Z.; Ni, S.; Shen, Z.X. Progress in aqueous rechargeable batteries. Green Energy Environ. 2018, 3, 20-41. [CrossRef]

5. Chou, S.-L.; Wang, Y.-X.; Xu, J.; Wang, J.-Z.; Liu, H.-K.; Dou, S.-X. A hybrid electrolyte energy storage device with high energy and long life using lithium anode and $\mathrm{MnO}_{2}$ nanoflake cathode. Electrochem. Commun. 2013, 31, 35-38. [CrossRef]

6. Wang, X.; Hou, Y.; Zhu, Y.; Wu, Y.; Holze, R. An aqueous rechargeable lithium battery using coated Li metal as anode. Sci. Rep. 2013, 3, 1401. [CrossRef] [PubMed]

7. Gao, H.; Goodenough, J.B. An Aqueous Symmetric Sodium-Ion Battery with NASICON-Structured $\mathrm{Na}_{3}$ $\operatorname{MnTi}\left(\mathrm{PO}_{4}\right)_{3}$. Angew. Chem. Int. Ed. 2016, 128, 12960-12964. [CrossRef]

8. Hou, Z.; Li, X.; Liang, J.; Zhu, Y.; Qian, Y. An aqueous rechargeable sodium ion battery based on a $\mathrm{NaMnO}_{2}-\mathrm{NaTi}_{2}\left(\mathrm{PO}_{4}\right)_{3}$ hybrid system for stationary energy storage. J. Mater. Chem. A 2015, 3, 1400-1404. [CrossRef]

9. Wu, X.; Cao, Y.; Ai, X.; Qian, J.; Yang, H. A low-cost and environmentally benign aqueous rechargeable sodium-ion battery based on $\mathrm{NaTi}_{2}\left(\mathrm{PO}_{4}\right)_{3}-\mathrm{Na}_{2} \mathrm{NiFe}(\mathrm{CN})_{6}$ intercalation chemistry. Electrochem. Commun. 2013, 31, 145-148. [CrossRef]

10. Bai, S.; Song, J.; Wen, Y.; Cheng, J.; Cao, G.; Yang, Y.; Li, D. Effects of zinc and manganese ions in aqueous electrolytes on structure and electrochemical performance of $\mathrm{Na} 0.44 \mathrm{MnO}_{2}$ cathode material. RSC Adv. 2016, 6, 40793-40798. [CrossRef]

11. Gupta, T.; Kim, A.; Phadke, S.; Biswas, S.; Luong, T.; Hertzberg, B.J.; Chamoun, M.; Evans-Lutterodt, K.; Steingart, D.A. Improving the cycle life of a high-rate, high-potential aqueous dual-ion battery using hyper-dendritic zinc and copper hexacyanoferrate. J. Power Sources 2016, 305, 22-29. [CrossRef]

12. Lu, K.; Song, B.; Zhang, J.; Ma, H. A rechargeable Na-Zn hybrid aqueous battery fabricated with nickel hexacyanoferrate and nanostructured zinc. J. Power Sources 2016, 321, 257-263. [CrossRef]

13. Wu, X.; Li, Y.; Xiang, Y.; Liu, Z.; He, Z.; Wu, X.; Li, Y.; Xiong, L.; Li, C.; Chen, J. The electrochemical performance of aqueous rechargeable battery of $\mathrm{Zn} / \mathrm{Na} 0.44 \mathrm{MnO}_{2}$ based on hybrid electrolyte. J. Power Sources 2016, 336, 35-39. [CrossRef]

14. Wang, L.-P.; Wang, P.-F.; Wang, T.-S.; Yin, Y.-X.; Guo, Y.-G.; Wang, C.-R. Prussian blue nanocubes as cathode materials for aqueous Na-Zn hybrid batteries. J. Power Sources 2017, 355, 18-22. [CrossRef]

15. Das, S.K.; Mahapatra, S.; Lahan, H. Aluminium-ion batteries: Developments and challenges. J. Mater. Chem. A 2017, 5, 6347-6367. [CrossRef]

16. Liu, G.; Chi, Q.; Zhang, Y.; Chen, Q.; Zhang, C.; Zhu, K.; Cao, D. Superior high rate capability of $\mathrm{MgMn}_{2} \mathrm{O}_{4} / \mathrm{rGO}$ nanocomposites as cathode materials for aqueous rechargeable magnesium ion batteries. Chem. Commun. 2018. [CrossRef] [PubMed]

17. Kundu, D.; Adams, B.D.; Duffort, V.; Vajargah, S.H.; Nazar, L.F. A high-capacity and long-life aqueous rechargeable zinc battery using a metal oxide intercalation cathode. Nat. Energy 2016, 1, 16119. [CrossRef]

18. Kraytsberg, A.; Ein-Eli, Y. The impact of nano-scaled materials on advanced metal-air battery systems. Nano Energy 2013, 2, 468-480. [CrossRef]

19. Zhang, J.; Zhao, Z.; Xia, Z.; Dai, L. A metal-free bifunctional electrocatalyst for oxygen reduction and oxygen evolution reactions. Nat. Nanotechnol. 2015, 10, 444-452. [CrossRef] [PubMed]

20. Mainar, A.R.; Leonet, O.; Bengoechea, M.; Boyano, I.; de Meatza, I.; Kvasha, A.; Guerfi, A.; Alberto Blázquez, J. Alkaline aqueous electrolytes for secondary zinc-air batteries: An overview. Int. J. Energy Res. 2016, 40, 1032-1049. [CrossRef]

21. Parker, J.F.; Chervin, C.N.; Pala, I.R.; Machler, M.; Burz, M.F.; Long, J.W.; Rolison, D.R. Rechargeable nickel-3D zinc batteries: An energy-dense, safer alternative to lithium-ion. Science 2017, 356, 415-418. [CrossRef] [PubMed]

22. Chamoun, M.; Hertzberg, B.J.; Gupta, T.; Davies, D.; Bhadra, S.; van Tassell, B.; Erdonmez, C.; Steingart, D.A. Hyper-dendritic nanoporous zinc foam anodes. NPG Asia Mater. 2015, 7, e178. [CrossRef]

23. Yan, Z.; Wang, E.; Jiang, L.; Sun, G. Superior cycling stability and high rate capability of three-dimensional $\mathrm{Zn} / \mathrm{Cu}$ foam electrodes for zinc-based alkaline batteries. RSC Adv. 2015, 5, 83781-83787. [CrossRef]

24. Pan, H.; Shao, Y.; Yan, P.; Cheng, Y.; Han, K.S.; Nie, Z.; Wang, C.; Yang, J.; Li, X.; Bhattacharya, P.; et al. Reversible aqueous zinc/manganese oxide energy storage from conversion reactions. Nat. Energy 2016, 1, 16039. [CrossRef] 
25. Delahay, P.; Pourbaix, M.; van Rysselberghe, P. Potential-pH Diagram of Zinc and its Applications to the Study of Zinc Corrosion. J. Electrochem. Soc. 1951, 98, 101-105. [CrossRef]

26. Persson, K.A.; Waldwick, B.; Lazic, P.; Ceder, G. Prediction of solid-aqueous equilibria: Scheme to combine first-principles calculations of solids with experimental aqueous states. Phys. Rev. B 2012, 85, 2569. [CrossRef]

27. Xu, C.; Chiang, S.W.; Ma, J.; Kang, F. Investigation on Zinc Ion Storage in Alpha Manganese Dioxide for Zinc Ion Battery by Electrochemical Impedance Spectrum. J. Electrochem. Soc. 2013, 160, A93-A97. [CrossRef]

28. Alfaruqi, M.H.; Gim, J.; Kim, S.; Song, J.; Pham, D.T.; Jo, J.; Xiu, Z.; Mathew, V.; Kim, J. A layered $\delta-\mathrm{MnO}_{2}$ nanoflake cathode with high zinc-storage capacities for eco-friendly battery applications. Electrochem. Commun. 2015, 60, 121-125. [CrossRef]

29. Hao, J.; Mou, J.; Zhang, J.; Dong, L.; Liu, W.; Xu, C.; Kang, F. Electrochemically induced spinel-layered phase transition of $\mathrm{Mn}_{3} \mathrm{O}_{4}$ in high performance neutral aqueous rechargeable zinc battery. Electrochim. Acta 2018, 259, 170-178. [CrossRef]

30. Lee, B.; Yoon, C.S.; Lee, H.R.; Chung, K.Y.; Cho, B.W.; Oh, S.H. Electrochemically-induced reversible transition from the tunneled to layered polymorphs of manganese dioxide. Sci. rep. 2014, 4, 6066. [CrossRef] [PubMed]

31. Alfaruqi, M.H.; Gim, J.; Kim, S.; Song, J.; Jo, J.; Kim, S.; Mathew, V.; Kim, J. Enhanced reversible divalent zinc storage in a structurally stable $\alpha-\mathrm{MnO}_{2}$ nanorod electrode. J. Power Sources 2015, 288, 320-327. [CrossRef]

32. Alfaruqi, M.H.; Islam, S.; Gim, J.; Song, J.; Kim, S.; Pham, D.T.; Jo, J.; Xiu, Z.; Mathew, V.; Kim, J. A high surface area tunnel-type $\alpha-\mathrm{MnO}_{2}$ nanorod cathode by a simple solvent-free synthesis for rechargeable aqueous zinc-ion batteries. Chem. Phys. Lett. 2016, 650, 64-68. [CrossRef]

33. Zhang, N.; Cheng, F.; Liu, J.; Wang, L.; Long, X.; Liu, X.; Li, F.; Chen, J. Rechargeable aqueous zinc-manganese dioxide batteries with high energy and power densities. Nat. commun. 2017, 8, 405. [CrossRef] [PubMed]

34. Sun, W.; Wang, F.; Hou, S.; Yang, C.; Fan, X.; Ma, Z.; Gao, T.; Han, F.; Hu, R.; Zhu, M.; et al. Zn/ MnO 2 Battery Chemistry with $\mathrm{H}^{+}$and $\mathrm{Zn}^{2+}$ Coinsertion. J. Am. Chem. Soc. 2017, 139, 9775-9778. [CrossRef] [PubMed]

35. Mukaibo, H.; Yoshizawa, A.; Momma, T.; Osaka, T. Particle size and performance of $\mathrm{SnS}_{2}$ anodes for rechargeable lithium batteries. J. Power Sources 2003, 119, 60-63. [CrossRef]

36. Lu, C.-H.; Lin, S.-W. Influence of the particle size on the electrochemical properties of lithium manganese oxide. J. Power Sources 2001, 97, 458-460. [CrossRef]

37. Drezen, T.; Kwon, N.-H.; Bowen, P.; Teerlinck, I.; Isono, M.; Exnar, I. Effect of particle size on $\mathrm{LiMnPO}_{4}$ cathodes. J. Power Sources 2007, 174, 949-953. [CrossRef]

38. Kraytsberg, A.; Ein-Eli, Y. Conveying Advanced Li-ion Battery Materials into Practice the Impact of Electrode Slurry Preparation Skills. Adv. Energy Mater. 2016, 6, 1600655. [CrossRef]

39. Minakshi, M.; Singh, P.; Issa, T.B.; Thurgate, S.; de Marco, R. Lithium insertion into manganese dioxide electrode in $\mathrm{MnO}_{2} / \mathrm{Zn}$ aqueous battery: Part II. Comparison of the behavior of EMD and battery grade $\mathrm{MnO}_{2}$ in $\mathrm{Zn}\left|\mathrm{MnO}_{2}\right|$ aqueous $\mathrm{LiOH}$ electrolyte. J. Power Sources 2004, 138, 319-322. [CrossRef]

40. Minakshi, M.; Singh, P.; Issa, T.B.; Thurgate, S.; de Marco, R. Lithium insertion into manganese dioxide electrode in $\mathrm{MnO}_{2} / \mathrm{Zn}$ aqueous battery: Part III. Electrochemical behavior of $\gamma-\mathrm{MnO}_{2}$ in aqueous lithium hydroxide electrolyte. J. Power Sources 2006, 153, 165-169. [CrossRef]

41. Jiang, B.; Xu, C.; Wu, C.; Dong, L.; Li, J.; Kang, F. Manganese Sesquioxide as Cathode Material for Multivalent Zinc Ion Battery with High Capacity and Long Cycle Life. Electrochim. Acta 2017, 229, 422-428. [CrossRef]

(C) 2018 by the authors. Licensee MDPI, Basel, Switzerland. This article is an open access article distributed under the terms and conditions of the Creative Commons Attribution (CC BY) license (http://creativecommons.org/licenses/by/4.0/). 